\title{
THE TRANSFORMATION OF THE WORLD
}

Volume 3: Culture and Thought 


\section{'THE TRANSFORMATION OF THE WORLD' SERIES}

General Editor: Anouar Abdel-Malek

This series is part of the United Nations University's project entitled Sociocultural Development Alternatives in a Changing World (SCA), directed by Project Co-ordinator Prof Dr Anouar Abdel-Malek, within the Human and Social Development Program of the UNU led by Vice-Rector Prof Dr Kinhide Mushakoji.

Spanish and Arabic versions of this series are being published by Siglo Vienteiunos XXI Editores, Mexico, and the General Egyptian Book Organization, Cairo, respectively.

Further volumes in the series are:

1: Science and Technology

2: Economy and Society

4: Religion and Philosophy

5: The Making of the New International Order: A Prospective 


\title{
THE TRANSFORMATION OF THE WORLD
}

\author{
VOLUME 3
}

\section{Culture and Thought}

Edited by

Anisuzzaman and

Anouar Abdel-Malek

\section{THE UNITED NATIONS UNIVERSITY}

IN ASSOCIATION WITH

M macmillan press ltd 
() The United Nations University 1983

English language edition @ Macmillan Press Ltd 1983

Softcover reprint of the hardcover 1st edition 1983

All rights reserved. No part of this publication may be reproduced or transmitted, in any form or by any means, without permission.

First published 1983 by

Scientific and Medical Division

MACMILLAN PRESS LTD

London and Basingstoke

Companies and representatives throughout the world

Typeset in Press Roman 


\section{Contents}

Preface

vi

Introduction xviii

I: Modernity in Crisis : The Resurgence of Tradition 1

II: Acculturation, Hegemony and National-cultural Identity 23

III: Social Power : The Emergence of New Socio-political Forces 40

IV: New Orientations : The Civilisational Dynamic 62

$\begin{array}{ll}\text { Orientations } & 80\end{array}$

Appendix 1: List of Participants $\quad 92$

Appendix 2: Papers $\quad 98$

Name Index $\quad 100$

$\begin{array}{ll}\text { Subject Index } & 102\end{array}$ 


\section{Preface}

There has been a gradual realisation over a period of time that the development efforts of the recent past have not enabled the masses of the people, particularly those who live in the Third World, either to raise their standard of living or to develop their own potentials. In these efforts the model of development was taken to be the Western world, and others, irrespective of their own peculiarities and the experience they gained in the course of history, were expected to follow the very same path that the West had taken. There was also a tendency to equate economic growth with improvement in the overall quality of human life. Both the assumptions have proved to be unfounded: the efforts have not yielded the expected results; on the contrary, the exercise has tended to perpetuate the dependence of the so-called underdeveloped areas on the developed areas. Within the national formations of the former, on the other hand, gains elsewhere have made the plight of the masses, the bulk of whom live in the rural areas, stand out more sharply than ever.

The Human and Social Development (HSD) Programme of the United Nations University (UNU), directed by Vice-rector Dr Kinhide Mushakoji, is, therefore, attempting to re-examine the conventional development wisdom. Those who are engaged in this Programme recognise that the solution of problems depends not only on technical knowledge, but also on a clear understanding of the causal relationship among the social, cultural, economic and political factors that determine the very nature of the problems. Accordingly, a project on 'Socio-cultural Development Alternatives in a Changing World' (SCA) was launched in mid-1978 by the HSD Programme of the UNU, with Professor Anouar Abdel-Malek of the Centre National de la Recherche Scientifique, Paris, as its .Co-ordinator, to bring out clearly the various and variant positions of the problem of human and social development that are rooted in different civilisations, cultures and nations and are determined by their objective conditions and historical specificity. Within a short time the Project has involved in its work people from various academic disciplines and also a variety of institutions in twenty countries in Africa, the Arab World and Asia, Europe and North and South America.

The SCA Project has been launched with a view to repositing the problematique of alternatives in human and social evolution as of the wide array of visions of our world, through its interwoven circles of civilisational moulds, geocultural areas, formations and nations. Quite naturally, each of these inter- 
woven circles comprises the socio-economic and political-ideological systems, as they obtain in the real concrete world of our times. Yet the SCA Project is oriented towards a deeper layer of analysis, deeper and also more compelling i.e. the combinatory of the civilisational and geostrategic levels. Only by combining these two levels - the more apparent, traditional, level of the social sciences and the wider and deeper level of civilisation and geostrategy - does it appear possible to reach for the hidden part of the iceberg, for the very roots of the formative alternative schools of thought and action, deep at work. Only thus do we appear to be able to mobilise their potentials towards a more humane, fraternal approach to the transformation of the world: precisely, the non-antagonistic dialectical treatment of contradictions leading towards complementarity.

The SCA Project is divided into two Sub-projects: one on 'The Endogenous Intellectual Creativity' (EIC), and the other on 'The Transformation of the World' (TW). While a series of symposia and seminars, starting with the first Asian Regional Symposium, held at the University of Kyoto (13-17 November 1978), followed by the Latin American Symposium at the Universidad Nacional Autonoma de Mexico (23-29 April 1979) and the Arab Regional Symposium at the University of Kuwait (7-11 March 1981) and their sequels, is devoted to the theme of the EIC Sub-project, the one on TW is being studied through a series of international seminars dealing with the major dimensions of the subtheme. The first such seminar, on 'Science and Technology', was held in Belgrade (22-27 October 1979); the second, on 'Economy and Society', in Madrid (15-19 September 1980); and the third, on 'Culture and Thought', in Algiers (13-17 December 1981). Two more international seminars, on 'Religion and Philosophy' and on 'History and International Relations', will follow in 1982.

In launching this series on the Sub-project of 'The Transformation of the World', there was an awareness that it fulfils an important part of the moral and scientific obligations of the international scientific community and of the United Nations University at the very heart of our joint quest for a New International Order, according to the fundamental decisions of the United Nations Organization and the Charter of the United Nations University, which coincide with the aspirations and decisions of the Group of Developing and Non-Aligned Countries. The systematic, comparative and critical study of the different dimensions of 'The Transformation of the World' is conceived of as the all-encompassing general frame and mould of the scientific and theoretical workshop now being developed, towards providing the international community with a deeper and more genuine understanding of linkages and differences, of our differing priorities, through their complex dialectical paths from contradictions to convergence. As such, this series of international seminars devoted to 'The Transformation of the World' wishes to implement the aims and ideals of the United Nations University, as defined in its Charter:

'The University shall devote its work to research into the pressing global 
problems of human survival, development and welfare that are the concern of the United Nations and its agencies, with due attention to the social sciences and the humanities as well as natural sciences, pure and applied.'

(Article I, point 2, UNU Charter)

'The research programme of the institutions of the University shall include, among other subjects, coexistence between peoples having different cultures, languages, and social systems; peaceful relations between States and the maintenance of peace and security; human rights; economic and social change and development; the environment and the proper use of resources; basic science and technology in the interests of development; and universal human values related to the improvement of the quality of life.'

(Article I, point 3, UNU Charter).

Perhaps it would not be inappropriate at this point to quote, at length, from the enunciation of the Project, made by Anouar Abdel-Malek, the Project Co-ordinator:

'The central character of our times, of the real world in our times, resides in the transformation - not evolution, or transition (all historical periods are periods of transition) - of all dimensions of the life of human societies. To be sure, this transformation, acknowledged by all quarters and groups all over the world, is neither unilinear nor synchronic. At the first level, we are witnesses to major differences in the quality and quantity, and, more so, in the tempo and impact, of processes of transformation in different sectors of social life and activity - economic production; patterns of power; societal cohesiveness; cultural identity; civilisational projects; political ideologies; religions; philosophies; myths; etc. - in short, all sectors of what is usually termed the infrastructure and superstructure of society. At a second, more visible and forceful level, we do acknowledge distinctions between different types of societies - e.g. in the different types of socio-economic formations and the accompanying political ideologies (basically capitalism, liberal capitalism and monopoly capitalism; and socialism, national progressive socialism and communism). And even more so, in the hitherto neglected dimension of civilisational, cultural and national specificity, we encounter major, more resilient and protracted sets of differences.

'This transformation of the world can be recognised in the following three sets of factors, which lend themselves to being recorded according to different conceptions of priorities.

(1) The resurgence of the three continents of Asia, Africa and Latin America to contemporaneity, in both the socio-political and civilisational-cultural fields. The historical processes of national liberation and independence, coupled with national and social revolutions, have gathered momentum since their inception in modern times, during the early part of the nineteenth century, until they became the dominant factor of contemporary history from the years following 
1917 and especially in the period 1945-1973. This vast transformation has been seen by Western specialists as a socio-political process within the traditional conception of the history of the world (as consisting of one centre, Europe, later Europe and North America: i.e. the Western world and its periphery, the Orient - Asia, Africa, the Arab-Islamic world, later joined by Latin America). The three continents were emerging but what was/is emerging is seen in sociopolitical terms.

'On the other side of the river, especially in the Orient (Asia, Africa and the Arab-Islamic world), this process of emergence was seen essentially as a process of renaissance of either culture or civilisation, as in the Arab and Islamic "Nahdah" and Meiji Japan, in the Chinese Cultural Revolution, and in the upsurge of Africanism; while Latin America's quest for identity has brought to light the hitherto hidden Indian and Indian-African elements of the culture.

(2) A parallel, major set of formative factors in this transformation appears to have developed between 1949 and 1973, and even from October 1917, the date of the first socialist revolution in history. The hitherto united front of the bourgeoisies in power was suddenly faced with the eruption of the labouring people into power, coupled with a populist Weltanschaung geared towards a persistently more humane life for the have-nots. Sixty years later, nearly half of mankind lives under socialism - four-fifths of whom belong to Asia and Africa.

(3) More recently, a third set of factors has become more visible, centring upon the immense progress accomplished in the fields of science and technology. Here again, while certain advanced Western countries opted for such denominations or descriptions as the "scientific and technological revolution" or "post-industrial society", on the other side of the river the vision remained paradoxically nearer to more realistic approaches, using the more traditional concepts of "revolution", "development", "social transformation", within the implacable parameters of geopolitics. Yet none would deny the message and ever-growing influence of the application of modern technologies in our world, in the very fabric of our individual life through the complexity of societal processes.

'The transformation of the world: how can it be related to the social and human sciences, to political and social theories, to the philosophical quest? And, proceeding from there, how can this lead the path towards a more comprehensive study of human and social development? To be sure, the prevailing position of the problematique of "The Transformation of the World" in our times starts with this third set of factors, around the visible impact and deep penetration of science and technology in all nations in our times - a redoubtable instrument for universalisation and reductionism that has compelled analysts, policy-makers and international organisations to devote their recent efforts to the study of this area. And while both the priority in the presentation of the three sets of formative factors and the tonality of this presentation are widely different, according to national-cultural and socio-political groupings in the world, nobody hesitates to acknowledge that science and technology have both 


\section{$x$

assumed perhaps primacy over the more restrictive level of economic production, being deeply at work as determining factors in armaments and geopolitics, culture and societal behaviour. In August 1980 the United Nations Organization Conference on Science and Technology for Development served as a focal point for the international deepening discussions of this area.

'The specificity of the Third International Seminar of our SCA Project of the United Nations University lies in its focus: this is a part of a whole series devoted to study of the structural modifications, to the remodelling, in depth, of the world, as we know it today, "Culture and Thought" being a major dimension to be tackled. This concept of "Culture and Thought" as a step and stage in the series devoted to the prospection of "The Transformation of the World" means that the stress and tonality of the Sub-project is more concerned with the differences, contradictions and tensions obtaining in this, our real world, than with more strictly ethical or development variables. Hence its persistent coupling of culture and thought with power, in the belief that the primacy of the political - the Prince as Philosopher - always at work in the history of men, ought to become the meeting point of scholars and policymakers, of specialists of culture and thought, on the one hand, with analysts and theoreticians of the science of man and society, on the other hand. A step, therefore, in an unfolding process, in interrelation with the parallel series of Endogenous Intellectual Creativity: more that intellectual and theoretical workshop we have in mind than a meeting of experts, sensu stricto. A long way, indeed, from the ethos and tonality obtaining in 1945 - a long, long way.

'Neither atomic clouds above the North Pacific, the hideous convulsions of traditional imperialism and colonialism in Asia and Africa, nor the liberation of the largest country in the world in 1949, could bring sense to the massive thrust in Western advanced industrial societies towards productivism, consumerism, hedonism. Finally, the Golden Age of man-as-demiurgos had been reached, the very frontiers of the Promethean concept so persistently at the heart of the Western civilisational project, from the age of maritime discoveries and the European Renaissance to Yalta. And the instruments of this historic fulfilment were none other, precisely, than science and technology as the driving forces in the second stage of the Industrial Revolution. If man was finally the master of Nature, the conqueror of the Universe, geared to achieve all the panoply of pleasures he could dream of, what, if any, would be the use in keeping such "archaic" concepts and moulds as nation, State, the family, working people and the tools of exploitation, to say nothing of such "distant" objective superstructures as philosophy, religion, the humane values of love and fraternity, equity and peace - let alone the civilisational project? In spite of the powerful waves making for the transformation of the world, few, or at best a large minority, were listening to the "voices of silence", to Joseph Needham's favourite Confucian saying, "Behave to every man as one receiving a great guest", to Chou En-Lai's "Don't forget the well-digger when you drink water". Or was it because of them? 
'Yet, in less than ten years, ethos and tonality have shifted decisively towards the penumbra of the "Crisis".

'Which crisis?

'In the North, leading epigones are busy mending fences. Oil, raw materials, the receding markets, non-competitive old industrial plants: such was the verdict, with some lonely exceptions. And this verdict was echoed by a large proportion of audible voices in the South, the good "Westernised modernisers", busily engaged in reciprocating, even if now with more strident voices.

'That the crisis could be that of Civilisation itself, was here and now mentioned. But this Civilisation was conceived of as that of the still hegemonic "centre", as against the underdeveloped or developing non-Western "periphery", provoking a mixture of reluctant and anguished self-interrogation. That the crisis might be, perhaps, that of the civilisational project of the hegemonic West itself, much more so than its actual hegemony and precedence, in power terms, began to emerge, here and there, followed by intense reactions of either apocalyptic previsions - if the Western civilisational project was in crisis, how on earth could mankind seek alternatives? - or derisive comparisons and strictures facing the incoherence and lagging behind of the non-Western world.

'For it is true that major parts of the underdeveloped non-Western societies are still caught in the mirage of reductionism, busily imitating the advanced industrial societies of the West, as if history was indeed repetitive, its formative historical moulds and real concrete processes amenable to copying, towards, precisely, limitless productivism, consumerism and hedonism, progress equated with profit and domination, the ghettos of individualism, the negative mind. As if nothing could be different from that very combinatory of factors eroding in depth self-assurance, popular and national self-reliance, the feeling of security, the hope for a more fraternal and equitable future for the majority of mankind - the taming of the "acquisitive society".

'Wherefore the quest for alternatives.

'In the field of science and technology, the quest is now towards "alternative technologies", or "appropriate technologies", with a sprinkle of "radical technologies". If a set of scientific applications, of technologies, is to be sought to escape the dilemmas of advanced Western industrialised societies, then, they could only be - in the reductionist approach - an "alternative" set of technologies, parallel to the advanced Western varieties. And this set could mercifully be located through the concept of "appropriate" technologies. "Appropriate" to what? "Appropriate" to whom? "Appropriate" for which purposes? "Appropriate" according to which and whose criteria? To be sure, history has it that the great majority of the nations of the Three Continents can hardly echo the procedures which enabled the West, in five centuries, through the concentration of historical surplus value, to gradually develop its modes of capital-intensive productivity. The humane uses of human 
resources, in the advanced nations of Asia, Africa and Latin America, as of the socio-economic restructuring of the societal fabric, is now seen to be more beneficial than hitherto imagined in bridging the gaps between rationality and fraternity, of giving a more humane vision of social dialectics than hitherto prevalent. Yet immense remain the temptations, traditions and fringe benefits of survival imitation, the reluctance to use vision as a tool for our futures. For then the question would be: To which technology does vision belong?

'The growing criticism of the impact of science and technology on modern societies and human life, through its diversity and different motivations, gives an impression of leading towards a growing ambiguity. For although this impact, through hegemony, had had its negative and pernicious effects in the underdeveloped areas, in the Three Continents of Asia, Africa and Latin America, to this day, whether through the direct domination of imperial powers or their more systematic pillaging by multinationals, the more recent mounting criticism has come from the developed areas, from the core of the West.

'The tonality here is of alarm, and the contents ethical and normative. Industrialisation and urbanisation have led to ecologism; atomic armaments and nuclear energy, to the quest for pacifism; consumerism and individualism, at the time of the energy crisis, to the pursuit of more humane, low-key participatory patterns of social interaction. And it is from the core of the more advanced industrialised societies of the West that the most ruthless indictments of science and technology are nowadays being launched.

'On the other side of the river, in Asia, Africa and Latin America, the mounting wave of national movements, often coupled with social transformation or revolution, has always clearly proclaimed its desire - in all countries, nations and societies in the so-called "South" - to achieve contemporaneity, to modernise, as of its variegated national-cultural specificities grounded in the depths of the historical field. And the instruments and means to achieve this global legitimate desire have been defined simultaneously, in the inner circle, as the creation and reinforcement, or revival, of a stable centre of national social power, the independent national State of the tricontinental area in our times, to be accompanied in the outer circle by careful analysis and assessment of the realities of the balance of power, of the evolving patterns of dialectical interrelations between major centres of power and influence in our times.

'For here, more than ever before, more than anywhere else, more than in any other field at any other time in the history of mankind, the massive unanimous protracted consensus of Asia, Africa and Latin America, of the Group of Developing and Non-aligned Countries, lies in the coupling of independent national power of decision, only feasible on the basis of an advanced level of science and technology in the fields of economic production, State structuring and the mass onslaught on illiteracy and backwardness, with a meaningful and equitable share in policy-making at world level. Such are the roots, visible for all to see, of U Thant's call for what was then labelled the "New International 
Economic Order", what has gradually become the "New International Order", at the time of the transformation of the world. A close scrutiny of major decisions and their philosophy in the series of major conferences from Bandoeng to Belgrade, Colombo and Havana, of the socio-political contents of the politics put forth by all national independent States of these areas, four-fifths of mankind, through the deep diversity of their socio-economic and political-ideological regimes, with the exceptions - isolated societies, or "comprador" fringes bears witness to this reality.

'The call has been and remains for a realistic political approach of human society in our times, a deep desire to fully use the contributions of science and technology as means to secure a wider and greater share in power of decision at world and regional levels, more often than not attuned to civilisational visions, cultural traditions and national parameters - but never evasive about the deep structural integrated interrelations between power and culture, at the heart of all problems of human and social development. As a matter of course, both sectors of world societies - the so-called North and the so-called South - meet along the more general issues, such as nuclear disarmament, or the acknowledgement of the need for more rational relations between the two sectors. But, short of the extreme parameters of annihilation, the rise to contemporaneity of Asia, Africa and Latin America is seen, by the formative endogenous schools of thought and action in these continents, in terms altogether different from those of the dedicated minority groups in advanced industrialised societies, who are justly rebelling against the dangers inherent in their society and its civilisational project. While, at the same time, the power structures of modern advanced industrialised societies, with the broad support of the wide masses of the population, including the working people, industry, agriculture, and the services alike, are in fact persistently taking action to reach an ever-growing level of scientific and technological sophistication in all fields of social life, with a view to ensure their continuous hegemony through the coming generations and, hopefully, centuries.

'Here lies the principal contradiction between "the two sides of the river", between the hegemonic power centres of advanced industrialised societies, on the one hand, and the rising national independent influence centres of the heretofore marginalised cultures and societies of the world. While the secondary contradiction seems to lie, at a much lesser degree of intensity and, perhaps, a higher level of ambiguity, between the humanistic minorities of advanced industrial societies, on the one hand, and the tricontinental area, on the other hand.

'Clearly, this area of contradictions is of crucial importance towards defining the problematique of our joint quest. It is here, so we feel, that the confrontation of analyses, the uses of meaningful comparatism, the perceptive understanding of different types and scales of priorities can be of genuine benefit for the international community, for deeper understanding of the transformation of the world in our times. It is here, so we feel, that the 
challenges and difficulties of the dialectics of tradition and modernity, specificity and universality, are calling upon us to search for the deepest roots, the hidden part of the iceberg, as it were.

'A task of vital importance in our times. An imposing challenge to the international intellectual community. The duty of all concerned citizens towards their nations, peoples and cultures.

'As Socrates, the master of interrogative dialectics, taught us, many a century ago, "everyone acts according to his knowledge". And we know that Louis Aragon is right when asserting that "the future has not already been lived". If knowledge, philosophical knowledge of the inner workings of societies in our time, is indispensable and worthy of continuous attention, could it be stated in confidence that a better knowledge, a deeper understanding of the present, both as history and as potential future, could chart the path towards more rational and humane endeavours?

'To this task of paramount importance, the historic task of bridge-building, our UNU Project "Socio-Cultural Development Alternatives in a Changing World" (SCA) is, above all, dedicated. For ours are the challenges and promise to jointly construct what we would propose to define as the gear-box of priorities: to bring together in meaningful interaction, towards complementarity, the widely different schools of thought and action in this, our world, rooted in civilisational, cultural, national specificities, socio-economic formations, political systems; philosophic, religious, ideological visions of the world; scientific, theoretical and methodological conceptions.

'As we approach the practical aspects of our research, the more practical, policy-oriented aspects of our endeavours, we are bound to face this basic dialectics between specificity and universality under the guise of what we would propose to call the dialectics of priorities. It is obvious that policy definition, differences in standpoints at programmatic and practical levels alike, relate directly to, and are grounded in, what appears at first sight to be a difference in priorities. Then how can we come to grips with this contradictory aspect of our problematique?

(1) The first level of analysis will deal with the definition of categories of priorities:

(a) Some would incline to put the first category in the domain of production, economics and their accompanying technological and scientific aspects. We would have here, inter alia, productivism and consumerism; low-key development and hedonism; individual patterns of economic organisation, and collective and State patterns; etc.

(b) The political dimension proper vividly obtains inasmuch as priorities take their shape through political decisions by the concerned bodies and institutions of all societies. Usual distinctions between liberal and autocratic, democratic and dictatorial, populist and despotic, consensus and elitist, etc. are naturally obtained and are of direct relevance to the definition of priorities. 
'(c) A third category can be located in the realm of culture, thought, philosophy, ideology, religion, as of their formative historical moulds: this is where we find the greatest number of differences, echoing the differentiation of human societies in nations, cultural areas and the proliferating Weltanschaung cutting across the different levels of this realm.

'(2) We would then address ourselves to a second level of differentiation, i.e. the different types of priorities:

(a) A first general type in priorities is the static-conservative type, i.e. the type of priorities more concerned with the maintenance of societal cohesiveness, socio-economic and political-ideological systems, either facing the mounting wave of new transformational and radical demands, or just as an expression of the necessity to preserve achievements and acquisitions which had been the results of lengthy processes of transformation before the crystallisation into a viable new order. The different legitimisations of this conservative approach clearly mean that the contents of what is sought to be conserved can be, and are, profoundly different - yet appear for a certain time more static than their proclaimed aims and contents.

(b) A second general type in priorities is the radical type oriented towards the transformation of societal moulds. Here priorities will often appear in parallel, dual, contradictory patterns, and not just as different stages in the same type of priorities, as is often the case in the conservative type of priorities.

'(3) Enough has been said, even though sketchily at this stage, to give a sense of the immense complexity of defining priorities, let alone making sense of their differences. Yet the most disconcerting aspect in priorities appears to be the aspect/dimension of tempi. For while the difference in priorities through their different categories and types - can be understood, and even accepted, as a rational discourse, the operational position of priorities through the time-dimension, i.e. the transition from choices to action, from decision to praxis, represents the hour of truth in the dialectics of priorities. And here again it is important to note that different tempi are not derived only from the subjective moment of decision-making: they are rooted, objectively, in the objectivity of the geohistorical constraints defined in the outer and inner circles of social dialectics in different societies of our world, as well as the different visions obtaining within these societies of the alternatives ahead of them.

(4) Wherefore the quest for a mediation which combines together the distinctions in a way that can make them understandable, acceptable to a reasonable extent, or at least properly perceived within their own objective legitimacies. The intent here is not to solve the dialectics of priorities but rather to clarify the hidden part of the iceberg which does forcefully make for contradictions, oppositions and frontal antagonisms. A central task of the SCA Project has therefore been seen as the gradual construction of the "gear-box of priorities", a gear-box whose component parts are none other than, precisely, the differentials representing the above-mentioned categories and dimensions of 
the dialectics of priorities.'

The third international seminar, on 'Culture and Thought', was held in collaboration with the Ministère de l'Enseignement Supérieur et de la Recherche Scientifique, Algeria, and was participated in by scholars from such diverse disciplines as history and philosophy, political science and economics, sociology and anthropology, international relations and literature, and from places far and near such as Algeria, Bangladesh, Bolivia, Chile, Egypt, Finland, France, Haiti, Hungary, India, Madagascar, Malaysia, Mexico, Norway, Poland, Sri Lanka, Tanzania, the UK, the USA, Venezuela and Yugoslavia.

The scope of the seminar was, admittedly, wide, as one would see from the frequently used terms and concepts such as civilisations, regions and nations; class, race and national minorities; modernity, tradition and culture; social, economic and political systems; ideology, philosophy and thought; religion, science and technology; class struggle, national liberation and power; equality, rationality and value system; diversity, specificity and universality; geopolitics, hegemony and dependence; world system, development and transformation. The views expressed by the participants also were, not unexpectedly, diverse, and, at times, contradictory. It was meant to be so, and it was a measure of the success of the seminar that it provided not only a meeting of the minds, but also a free flow of ideas in a very conducive atmosphere. There was, nevertheless, a surprising degree of agreement that the conceptualisation and methodology of the contemporary social sciences were inadequate in responding to the demands of our times. More questions were, perhaps, raised in the seminar than were answers given, but in several areas there was a concurrence of forcefully expressed views. The simple dichotomy between tradition and modernity was challenged and criticised from many angles, it being argued that both the terms should be seen as conceptions in plural. The depository of post-enlightenment Western thought as representing the core of a universal principle of rationality around which human beings could organise their thought and action was called into question. Similarly, the need was emphasised for a renewed thinking on many of the received theories of Marxism in the light of contemporary historical experiences. The participants underscored the necessity of studying, in a larger context, the social, economic, political and cultural processes of the areas of the world other than their own, and of cross-fertilisation of concepts, ideas and results of empirical research to provide an objective base for devising effective strategies for the transformation of the world. It was agreed on all sides that to achieve a genuine transformation of the world thought and action were needed to be directed towards dismantling the structures of domination - not only those between the nations, but also those within each national society so that a more egalitarian, more plentiful and more democratic world can be ushered in.

An attempt has been made in the following pages to present to the general reader the substance in English of the papers presented and interventions made in the Algiers seminar - the original ones having been made in the Arabic, 
English, French and Spanish languages. In doing so the editors have tried to be as objective as possible in representing the views of the participants. The views expressed herein are those of the participants and of the editors, and they do not necessarily reflect the views of the nations or institutions they belong to nor those of the United Nations University. And a final word: the present work is not intended as a substitute for a larger volume that will be published as the proceedings of the seminar and include all the papers in their original or revised forms, as may be chosen by their authors.

The editors would like to place on record their sincere appreciation of the ungrudging assistance received from Madame Christine Colpin and Ms Sanya Aroussy in the preparation of this book. 


\section{Introduction}

They had gathered in a vast conference room of an Algiers hotel: thirty or so men and women, with very different backgrounds. They had come from various parts of the world: Western Europe and North America, East Europe and Africa, Asia and Latin America. The obvious signs of fatigue after international travel seemed to have been wiped away by the warm hospitality offered by the Algerian hosts. Instead there were signs of expectation at the prospect of meeting friends and acquaintances and getting to know others and signs of eagerness at the prospect of a lively discussion to ensue. If anyone suffered from the apprehension of failure to do his best or of getting bored by speakers who had never learnt to stop, it was effectively concealed. But everyone was aware of the responsibility vested in him by the United Nations University in its efforts to build bridges among the scholars from far and near so that their collective wisdom could contribute to tackling the global problems facing humanity today.

The inaugural ceremony was brief and solemn. Dr Djamil Benbouzid, Director of Scientific Research to the Ministry of Higher Education and Scientific Research in Algeria, welcomed the participants on behalf of the Minister, Dr Abdelhaq Brerehi. Referring to the ties already existing between the Ministry and the UNU, he said that the choice of Algiers as the venue for this important international seminar reflected the interest of the international community in Algeria and its research works. Benbouzid hoped that the seminar, which would address itself to the pressing problems of the day and a vision of the future, would help guide the developing countries towards genuine paths of development and create the vision of a new man rooted to the real social setting and environment.

In his opening address to the participants, as also to the members of the audience who had gathered there to listen to the deliberations, Anouar AbdelMalek, the Co-ordinator of the SCA Project, said: 'Reflecting on the experience of the United Nations University's Project on "Socio-cultural Development Alternatives in a Changing World", and particularly so of its Sub-project on "The Transformation of the World", at the end of the Second International Seminar devoted to the implementation of "The Transformation of the World" Subproject, dealing with the dimension of "Economy and Society in the Transformation of the World" in Madrid from 15 to 19 September 1980, a little more than a year ago, it was felt that the identification of problematic areas, little tackled till now, could comprise the following:

(a) The conception of progress seen as a succession of "stages". 
(b) The historicity of progress, as compared with the universal dimension of social evolution.

(c) The differentiation of societal groups, in classes, categories, professional groups, trends, plus the regional and local diversification.

(d) The formation of social ethos as compared with social philosophies and ideologies.

(e) The biological factors in societal processes, essentially gender, age, especially seen in the relations to social power and visions of the world, etc.

(f) The requisites of a realistic, real concrete, philosophical approach to the problems of economy and society as the fabric of the endogenous, inner, circle of the transformation of the world.

'(g) The transition from the contemplative, ethically oriented scientist to the new type of scientist and intellectual as responsible citizen: his required training in economy, geostrategy, social and political planning, philosophy.

'(h) The question of how, if "man does not live by bread alone", a more perceptive planning of the economic and social cadres responsible for the future could take into account the non-economistic dimension of human life, generally under the label of "superstructure", but genuinely made of philosophy, religion, ideology, spirituality, in general.

(i) The question, after the failures now clearly perceived of the economistictechnicist approach, of what could be the prospects of culture and spirituality in the reshaping of the socio-economic fabric of human societies at the times of the transformation of the world.

'(j) The question what can be the place and role of vision, artistic imagination, dream, mysticism - as related to our real concrete approaches.'

Having thereafter briefly explained the perspectives of the Project, he proceeded to say:

'We cannot here present the whole range of activities of the two International Seminars which have already prospected the dimensions of "Science and Technology", "Economy and Society". Documents to that effect will be found in the different series of the SCA Project Publications at the United Nations University Press, and will soon be available for the wide public, in both hardback and paperback format. At the same time, the guidelines for this, our Third International Seminar, devoted to the investigation of the dimension of "Culture and Thought in the Transformation of the World", have clearly brought together the continuity of the process of investigation undertaken, thus introducing the four themes of each of the four sections of this, our Third International Seminar, in Algeria. During the days ahead, as of this sunny and shining morning, we shall investigate, one by one, the four successive themes:

'Modernity in crisis: the resurgence of tradition.

'Acculturation, hegemony and national-cultural identity.

'Social power: the emergence of new socio-political forces.

'New orientations: the civilisational dynamic.

'Our eminent friends and colleagues at the Committee of Honour suggested 
that we would centre this Third International Seminar on the interrelation between "tradition and modernity". They felt, and we all deeply concur with them, that this was indeed the heartland of the problematique, beyond the more traditional problems and difficulties of the making of the new world order, the core area for our joint intellectual exploration and scientific investigation of that hidden part of the iceberg which, to a large degree, could help define and shape, or hinder, the forms and contents, the tempo, too, of the transformation of the world.

'A guiding thread, indeed. For the philosophy of the SCA Project has always been and shall remain, to give voice to the representatives of the formative alternative schools of thought and action at work in the different civilisational, geocultural and national moulds of this, our changing world, which implies the principled legitimacy of all these visions, the refusal of Manichaeism, the fraternal, concerted effort to build together that "gear-box of priorities" which, hopefully, could make sense of our differences and diverging scenarios and policy formulations. Here again, once again, there is no royal road: specificity will not "wither" away by a stroke of transnational voluntarism. On the contrary, we are witnessing a resurgence of the dimension of specificity, deeply rooted in our different histories, as they have concretely obtained, facing the menaces of reductionism and hegemonism. As our recent International Symposium on the Convergence Area dealing with "Specificity and Universality", held in Tokyo from 9 to 13 November 1981, has shown, the dialectics of specificity and universality, the one and the many, diversity and unity, appears of the highest complexity, and yet, literally, vital to the structuring of the new world order, more equitable and humane, away from the nuclear holocaust.

'It is therefore no coincidence that this Major Meeting of the SCA Project of the United Nations University is being held at the very heart of the Mediterranean area, where civilisations and continents have been meeting, in a subtle, always tense and mutually enriching civilisational dialectics, for more than thirty centuries.

'Wherefore the tonality and promise of our joint quest. Thank you all from the heart, and good luck!'

Mr Soedjatmoko, Rector of the United Nations University, who was expected at the opening session, arrived late for that. He delivered his address on the next day, but that gave him the opportunity to offer a little more, as he explained himself:

'It provides me with an opportunity to express, however belatedly, my pleasure and the honour I feel about being here, and to add my words of welcome to those of the Chairman at the opening session. Speaking now, at the same time, gives me a different kind of opportunity, namely to interact with you as a participant, and it is an opportunity I welcome very much. Especially because of the importance of this meeting. Its importance is in a sense demon- 
strated by the fact that this conference has been able to bring together all of you, people of intellectual stature and prominence in a variety of fields. I believe that it was our awareness of the importance of the subject matter that has added to the attraction of Algerian hospitality for all of us to come to Algiers.

'I am quite sure that the importance of the topic in our own minds has something to do with the increasing awareness among all of us of the extent to which economics, the social sciences, as well as philosophy have been unable to adequately explain human and collective behaviour in the past twenty years. Neither have they been able to make any informed projections about future behaviour. The reasons for this are obvious, but require much more rigorous analysis. There is in the first place, of course, the increasing complexity of the various processes of the social change. There is also the increasing rate of change, the increasing rapidity and the scale of social change. Another reason is that factors that have been neglected in social theory turned out to have a much more profound impact on social change than expected. The role of religion is a case in point, and generally the very profound shift in values taking place in different directions and in different places in the world. We have also seen the manifestation of the erosion and malfunctioning of many institutions, including the State itself, profoundly affecting the dynamics of social change and global transformation.

'All this requires us to review our present arsenal of conceptual tools and intellectual categories of thought. We will have also to review the relevance of our conventional dichotomies and possibly reconceptualise much of our ways of relating to social reality and change.

'It is with this in mind that $I$ have followed the discussions so far quite intently. I have enjoyed the opportunity to listen to a large number of important statements. If I may say so, however, I have also been struck by what was not raised in the discussions. I should like to limit my intervention to a discussion of some of these points.

'One major item which I felt was missing was a discussion of the impact of modern communications on social processes and on institutions to the point where communications have become a major factor contributing to their erosion. This raises questions about the impact of modern communications on the capacity of a system towards solidarity-making and towards developing and maintaining an adequate capacity for social and political cohesion. Inevitably we shall have to look at the modes in which the images are formed through which we reconstruct social reality in our minds, and develop the conceptual tools for our understanding of that reality. It leads us into the need for semantic analysis of our concepts in the social sciences and also for a deeper historical and comparative analysis of the social sciences as a social phenomenon itself. In addition, it has become clear that as social change does not take place within specific social systems in isolation but as a result of the pervasiveness of communication and information, we shall have to study the processes of 


\section{xxii Culture and Thought}

solidarity-making within the context of interdependence, and specifically within the context of the interaction between universalising tendencies and tendencies towards cultural specificity. We are therefore dealing with problems of selfreliance, not through decoupling or through development in isolation, or in any autarchic sense, but through the proper management of interdependence. This forces on each civilisation the necessity to constantly redefine itself in terms of the changing values resulting from the impact of science and technology, high energy cost, communications and the impact of biotechnology. In doing so, each culture will have to confront the basic questions that determine its essential character (or, one might say, prefigure the perception of the experience of reality) - that is, the culture conceptions of death, love, loyalty, courage, purpose and meaning of life and the use of force. The redefinition of these fundamental concepts is a difficult and painful process which each culture will have to undertake in constant interaction with the outside world without losing a sense of cultural continuity. In other words, at the political level ideology should be nationally relevant and internationally viable or credible. We therefore need a communications theory of social transformation. This might help us to explain more adequately the phenomenon of the "State" in the Third World: its power; the relations within it, between those who support the social political system and those who don't; the patterns of distribution of power, and how these affect patterns of technology choice and of industrialisation.

'The second item which I felt was missing was a discussion of the process of increasing militarisation, the increasing tendency to resort to arms in a polarised world, but also, at the national level, the increasingly easy access to the means of violence. It is obvious that the process of militarisation and reliance on arms is not limited to the role of the armed forces. What we are dealing with is a process of militarisation of society in general, and the impact this has on processes of social transformation. It should be noted that at the same time new expressions of commitment to non-violence are also emerging. The process of militarisation also has affected the world of science. One might say that the area of scientific information is becoming increasingly a closed one, because of the increasing control and participation of the military in the development of science and technology. Not only the roles of military research and development, but also of the think-tanks and institutes of strategic studies, and the fields of information science and electronics, have shown increasing intrusion and control by the military. In this regard, we should also look at the area of cryptology. This is bound to have a profound impact on the development of ideas that govern a society's perception of itself and its surrounding reality.

'These are some of the considerations that came to mind as I was listening to the discussions. We cannot disregard the increasing violence, at the subnational, national and international levels, that accompanies these processes of social transformation, and we have to be able to understand the internal dynamics of our societies much better, and also their interaction with the environment in which they function. I hope that my intervention will contribute 
Introduction $x x i i i$

to a discussion of these, in my view, rather important points.'

The discussions, as indicated above, had already begun then: papers were presented, interventions were made and reports were to follow. 